\title{
SUBJETIVIDADES
}

Especial:

Psicologia \& Fenomenologia

\section{PROPOSIÇÕES PARA UM MÉTODO FENOMENOLÓGICO HERMENÊUTICO PARA A PESQUISA DE CAMPO}
Propositions for a Hermeneutic Phenomenological Method for Field Research
Proposiciones para un Método Fenomenológico Hermenéutico para la Investigación de Campo

\section{Propositions pour une Méthode Herméneutique Phénoménologique pour la Recherche sur le Terrain}

10.5020/23590777.rs.v21iEsp1.e11305

\begin{abstract}
Ana Maria Monte Coelho Frota (iD) 9
Psicóloga, mestre em educação, doutora em psicologia, com estágio pós-doutoral na UFRN, professora titular da Universidade Federal do Ceará, vinculada ao Programa de Pós-graduação em Educação Brasileira, membro do Grupo de Trabalho Psicologia e Fenomenologias da ANPEP.
\end{abstract}

\section{Elza Maria Socorro Dutra iD 9}

Psicóloga, Professora Titular em Psicologia Clínica Fenomenológica -PPgPsi-UFRN, com estágio pós-doutoral na UFF. Coordenadora do GT- Psicologia \& Fenomenologia- ANPEPP, líder do GESDH- Grupo de Estudo Subjetividade e Desenvolvimento Humano- UFRN/CNPq.

\section{Resumo}

Este artigo trata de reflexões acerca da construção de um método de pesquisa em psicologia inspirado na filosofia de Martin Heidegger. Para tanto, inicia discutindo sobre a fenomenologia. Em seguida, debruça-se sobre Heidegger, discutindo brevemente alguns elementos de sua ontologia, sempre no sentido de aproximação de um caminho possível de pesquisa fenomenológica que se oriente nessa direção. Finalmente, apresenta o círculo hermenêutico, tal qual proposto por Heidegger, sugerindo possíveis caminhos de pesquisa fenomenológica com inspiração heideggeriana. Mais do que apresentar um modelo de pesquisa, procura abrir discussões geradoras de novas reflexões.

Palavras-chave: hermenêutica; psicologia fenomenológica; metodologia; círculo hermenêutico.

\section{Abstract}

This article deals with reflections on the research method construction in psychology inspired by Martin Heidegger's philosophy. Therefore, it starts by discussing phenomenology. Then, it turns to Heidegger, briefly discussing some elements of his ontology, always in the sense of approaching a possible path of phenomenological research that orients in this direction. Finally, it presents the hermeneutic circle, as proposed by Heidegger, suggesting possible ways of phenomenological research with Heideggerian inspiration. More than presenting a research model, it seeks to open discussions that generate new reflections.

Keywords: hermeneutics; phenomenological psychology; methodology; hermeneutic circle.

Resumen

Este trabajo trata de reflexiones acerca de la construcción de un método de investigación en psicología inspirado en la filosofía de Martin Heidegger. Para eso, se inicia discutiendo sobre la fenomenología. Después, se dedica a Heidegger, discutiendo un poco sobre algunos elementos de su ontología, siempre en el sentido de acercamiento de un camino posible de investigación fenomenológica que se orienta en esta dirección. Finalmente, presenta el circulo hermenéutico, tal cual propuesto por Heidegger, sugiriendo posibles caminos de investigación fenomenológica 
con inspiración heideggeriana. Más que presentar un modelo de investigación, busca abrir discusiones generadoras de nuevas reflexiones.

Palabras clave: hermenéutica; psicología fenomenológica; metodología; círculo hermenéutico.

\section{Resumé}

Cet article porte sur des réflexions sur la construction d'une méthode de recherche en psychologie inspirée de la philosophie de Martin Heidegger. Par conséquent, il commence par discuter de la phénoménologie. Ensuite, il se tourne vers Heidegger, discutant brièvement des certains éléments de son ontologie, toujours dans le sens d'aborder une voie possible de recherche phénoménologique qui s'oriente dans cette direction. Enfin, il présente le cercle herméneutique, tel que proposé par Heidegger, en suggérant des voies possibles de recherche phénoménologique d'inspiration heideggerienne. Plus que de présenter un modèle de recherche, il cherche à ouvrir des discussions qui génèrent de nouvelles réflexions.

Mots-clés : herméneutique ; psychologie phénoménologique ; méthodologie ; cercle herméneutique.

Sabendo-se que este artigo trata de pensar uma estratégia de pesquisa baseada em ideias da fenomenologia hermenêutica proposta pelo filósofo Martin Heidegger, é oportuno que, inicialmente, façamos um passeio pelo pensamento de William Dilthey, a quem se deve a distinção entre ciências naturais e ciências do espírito, sendo nesta última que se situa um provável método de pesquisa tal como proposto aqui. Para começar, apresentamos uma citação de Casanova (2011, p. 11), que afirma, de modo contundente, a diferença entre as ciências naturais e as ciências do espírito, como definidas por Dilthey:

Assim, as ciências naturais são essencialmente marcadas pela produção de uma cisão entre o fenômeno e a vida, entre o campo de investigação de seus objetos e o nexo vital histórico, material e psíquico no qual esses objetos eles mesmos desde o início se encontram. Ciências naturais são decompositoras, destrutivas e esfaceladoras. Em suma, elas trabalham por meio de um procedimento abstrativo, que traz consigo inevitavelmente uma desvivificação dos conhecimentos. E esse é o cerne da afirmação diltheyana de que ciências naturais são explicativas, enquanto as ciências humanas são compreensivas. Para Dilthey, as ciências naturais são explicativas, na medida em que procuram dar conta de maneira teórico-causal do modo de ser daquilo que se apresenta. Em contraposição a esse comportamento explicativo das ciências naturais, as ciências humanas são compreensivas, porque elas trabalham justamente na direção da reconstrução da base comum a partir da qual se realizam todos os fenômenos em geral.

A partir dessa afirmação, uma questão que se apresenta seria: como desenvolver pesquisa sem que se adote os parâmetros cientificistas, principalmente se pensarmos o rigor científico? Por exemplo, no que se refere às pesquisas, na perspectiva fenomenológica, jamais os critérios de rigor científico serão adotados como parâmetros, pois sabemos que, ao eliminar a dualidade sujeito-objeto e corpo-mente, o fenômeno sobre o qual nos debruçamos não será alcançado, conhecido ou analisado de forma estática e objetiva. Sempre será uma apreensão de uma verdade imediata e provisória. No entanto, pensando a historicidade, seria esse horizonte histórico, no qual estamos imersos e que nos constitui, que forneceria a possibilidade de pensar de forma mais geral o mundo.

Continuando a reflexão na mesma direção, Casanova (2011, p. 13) refere-se a Dilthey a respeito do seu entendimento de uma ciência do espírito. E diz:

Tudo o que se mostra no interior do mundo, para Dilthey, desde as dimensões mais diminutas do inorgânico até as estruturas mais complexas do pensamento discursivo, se apresenta no interior de um horizonte histórico-hermenêutico prévio e alcança sua determinação propriamente dita a partir apenas de tal horizonte.

Tal afirmação remete à historicidade, defendida pelo filósofo Martin Heidegger (1927/2015) em sua analítica da existência, e ao círculo hermenêutico, à visão prévia especificamente. O sentido sempre repousará num contexto de mundo e, inevitavelmente, também desvelando a impessoalidade, pois sempre estaremos sentindo e vivenciando as situações a partir ou com aquilo que constitui o mundo histórico. Como diz Casanova (2011, p. 13) sobre a experiência de existir, "se confunde com a visão de mundo dessa época, ideia que é complementada pela fala seguinte:

Como minhas vivências me colocam incessantemente em ligação com a vida histórica de meu tempo e como essa vida histórica 
aponta para as concreções objetivas do espírito em cada época, tudo o que faço, penso, imagino, sinto e represento, assim como tudo o que deixo de fazer, possui uma ligação umbilical com a visão de mundo, ou seja, expressa essa visão. (Casanova, 2011, p. 14)

Ao distinguir as ciências naturais das humanas, Dilthey (2011, p. 32) refere-se, frequentemente, à vida. Na frase seguinte, vemos a explicitação dessa ideia: “(...) e com isso, para a cisão crescente da vida em relação ao saber”. A partir disso, o autor sugere duas opções para a psicologia: submeter-se às ciências naturais, ao adotar as suas bases hipotéticas ou "elas tentam resolver suas tarefas sem a base de alguma visão panorâmica cientificamente ordenada qualquer sobre os fatos psíquicos, só apoiadas sobre a psicologia ambígua e subjetiva da vida" (Dilthey, 2011, p. 32).

Essa ideia e esse argumento são fundamentais para justificar um método que leve em conta, e de maneira radical, uma ontologia fundamental. Tal método, como aquele inspirado por Heidegger sobre o qual estamos tematizando neste artigo, pode ser respaldado pelo pensamento de Dilthey na medida em que uma ciência do espírito, como nomeia o filósofo, tem como caminho a compreensão, e a fenomenologia hermenêutica, representada aqui pelo que o filósofo Martin Heidegger, atribui ao Dasein, originariamente, a capacidade de compreender o seu próprio ser.

Dentre as diferentes possibilidades de pesquisa qualitativa, o método fenomenológico de inspiração heideggeriana representa um caminho possível para pesquisadores que se identificam com as ideias da analítica da existência, propostas pelo filósofo Martin Heidegger. Tal modo de abordar a pesquisa consiste numa perspectiva direcionada para a experiência, enfatizando a dimensão existencial do viver, e buscando, antes de tudo, a compreensão dos sentidos desvelados pelos sujeitos na sua condição de seres-no-mundo.

Nessa perspectiva, a experiência é entendida como a própria existência, já que ek-sistere significa estar para fora, ser para fora, como bem o diz o filósofo ao propor o Dasein como um ser-no-mundo (Heidegger, 1927/2015). Assim, consideramos que compreender a experiência de alguém é acessar a dimensão existencial do vivido, dado que ela nos remete ao vivenciado pelos sujeitos. Esta é a ideia primeira da fenomenologia, qual seja, um "voltar às coisas mesmas". Com tal ideia em mente, este trabalho tem o intuito de pensar uma estratégia de pesquisa, tomando como fundamentos as ideias do filósofo Martin Heidegger e a sua analítica da existência (Heidegger, 1987/2001, 1927/2015), que tem na noção de existência (ek-sistere) a sua ideia basilar.

Vale a pena ressaltar que a reflexão acerca de uma metodologia de pesquisa inspirada na fenomenologia é recente. Segundo DeCastro e Gomes (2011), nos últimos vinte anos, vem ocorrendo um grande aumento na aplicação do método fenomenológico na pesquisa empírica aplicada à psicologia. Para eles, a partir de um levantamento das pesquisas realizadas entre os anos de 1996 e 2007 (Brasil) e de 2007 a 2008 (no periódico norte-americano Journal of Phenomenological Psychology), 55 artigos foram produzidos, evidenciando a pluralidade lógica e técnica na aplicação da redução fenomenológica. Desse modo, "Husserl com fenomenologia transcendental, Merleau-Ponty com a existencial, Ricoeur e Gadamer com a hermenêutica, Derrida com a linguística e Lévinas com a fenomenologia ética" (DeCastro \& Gomes, 2011, p. 155), apontam caminhos para se pensar a construção de um método fenomenológico, inspirado nas suas ideias. No entanto Heidegger não aparece em nenhuma das pesquisas levantadas. Essa carência de estudos inspirados na fenomenologia heideggeriana por si só, já se configura como um elemento que corrobora para a necessidade de mais estudos e reflexões. Além disso, no parágrafo 7 de Ser e Tempo, Heidegger (1927/2015, p. 66) já nos aponta que "apreender o ser dos entes e explicar o próprio ser é tarefa da ontologia. O método da ontologia, no entanto, permanecerá altamente questionável caso se queria recorrer às ontologias historicamente dadas ou a tentativas congêneres". Desse modo, o caminho a ser seguido se distancia do caminho da história das ontologias e se volta para um retorno às coisas mesmas, por elas mesmas: “(...) para as coisas elas mesmas!”, afirma o filósofo da Floresta Negra (Heidegger, 1927/2015, p. 66). No entanto, segue advertindo:

Isso, porém, não significa que o tratado prescreva um ponto de vista ou uma corrente. Pois, enquanto se compreender a si mesma, a fenomenologia não é e não pode ser nem uma coisa nem outra. A expressão fenomenologia significa antes de tudo um conceito de método. Não caracteriza a quididade real dos objetos da investigação filosófica, o que dos objetos, mas o seu modo, o como dos objetos. Quanto mais autenticamente opera um conceito de método e quanto mais abrangentemente determina o movimento dos princípios de uma ciência, tanto mais a originalidade em que ela se radica numa discussão com as coisas ela mesmas e tanto mais se afastará do que chamamos de artificio técnico, tão numeroso em disciplinas teóricas. (Heidegger, 1927/2015, p. 66)

Evidenciamos aqui a existência de uma diversidade de fenomenologias. Muitos estudos são feitos a partir de fenomenologias empíricas, como o de Moreira e Souza (2016), que se debruçou sobre o método fenomenológico de Amedeo Giorgi; Andrade e Holanda (2010), que dão uma visão panorâmica do método fenomenológico, detendo-se em Amedeo Giorgi; Feijoo e Goto (2016), refletindo sobre uma metodologia de pesquisa husserliana; e Moreira (2004), pesquisando a partir da fenomenologia de Merleau Ponty. Contudo muito pouco se produziu acerca do método de pesquisa com orientação heideggeriana. 
Este artigo se propõe a trazer proposições acerca do método fenomenológico hermenêutico, com a intenção de ampliar a discussão e incrementar a pesquisa fenomenológica inspirada em Heidegger. É uma proposta inovadora, ousada e, ao mesmo tempo, fértil.

Heidegger inaugura uma fenomenologia hermenêutica, à medida que toma o Dasein como ponto de partida para qualquer pergunta, oferecendo um caminho para a fundamentação necessária para a produção do conhecimento. Interpretando a facticidade desde si mesmo, o filósofo insiste na radicalidade ontológica de sua problemática. Sua fenomenologia hermenêutica, atesta Stein (2014, p. 207), "sem significar um ataque à razão, representava a dimensão da historicidade em que essa razão se apoiava, na medida em que sempre já pressuponha a dimensão do compreender". Trouxe, de forma inovadora, a certeza da impossibilidade de recusar o caráter radical de historicidade das condições de conhecimento, tornando-se o primeiro filósofo a dar forma à hermenêutica nos anos 20. Assim, a obra seminal de Heidegger (1927/2015), Ser e Tempo, apresentou-nos a fenomenologia hermenêutica, da qual trataremos neste artigo.

Visando a tal objetivo, consideramos oportuno retornarmos brevemente à origem das ideias fenomenológicas desde o seu advento, com Edmund Husserl ${ }^{1}$, isso porque, desde então, muitos filósofos levaram adiante as suas ideias, embora, não raro, alguns tenham percorrido caminhos distintos e até opostos àqueles traçados pelo criador da fenomenologia, tais como o filósofo Martin Heidegger.

\section{Fenomenologia como uma Via de Conhecimento}

E o que vem a ser a fenomenologia? Resumidamente, refere-se ao estudo do fenômeno, o qual, por sua vez, pode ser entendido no seu sentido estrito como aparecer, ou aquilo que se mostra por si mesmo, partindo do grego phainestai. Com isso, não existe um fenômeno puro, visto que a forma como o apreendemos está diretamente ligada aos nossos valores, à nossa história, o que reafirma a negação da neutralidade na pesquisa.

Ela surge em oposição ao positivismo (Heidegger, 1927/2015), em que o conhecimento é considerado válido quando os conceitos são construídos a partir de parâmetros lógicos e com a garantia de privação da intimidade entre os homens e o mundo. Por sua vez, a fenomenologia acredita que o conhecimento é possibilitado por meio da aceitação dessa intimidade e do envolvimento entre homem e mundo. Busca algo muito diferente do conhecer metafísico, que pretende dominar o conteúdo de uma matéria ou disciplina (Critelli, 1996).

Na metafísica tradicional, considera Critelli (1996), há distinção entre o ser das coisas e a aparência destas. Já para a fenomenologia, o que se mostra, ou seja, a aparência, é o próprio fenômeno sujeito à produção do sentido dado pelo intérprete. Na sua aparição, o fenômeno mostra-se carregado de todos os sentidos a ele atribuídos, que se interliga à história, cultura e sociedade da qual faz parte. Para a fenomenologia, portanto, não existe uma verdade absoluta, já que conhecemos e habitamos nada mais do que uma representação do mundo.

A fenomenologia, ao surgir com Husserl, ultrapassa o modelo cartesiano e a perspectiva metafísica da tradição, negando a existência de uma verdade universal, pura e imutável, possível de ser alcançada pelo homem através da razão (Husserl, 1900/2014a, 1901/2014b). Husserl, apesar de buscar uma compreensão do mundo e de seus fenômenos de um modo rigoroso, se distancia de Descartes ao fazer a suspensão do sujeito empírico. Assim, se distancia do modelo da ciência moderna, sendo considerada como uma filosofia, um método e uma epistemologia. Assim, reitera Silva (2018), a fenomenologia não parte de pressupostos metafísicos.

É importante salientar que o problema epistemológico enfrentado por Husserl sugere fortemente a não fragmentação entre sujeito e objeto, que demarca claramente a diferenciação com outras epistemologias e filosofias.

No entanto vale dizer que o pensar fenomenológico não é privilégio somente dos filósofos, assegura Critelli (1996). O método fenomenológico passou a fazer parte de outros campos de saberes, tais como a psicologia, tendo como objetivo capturar o sentido ou significado da vivência e experiência das pessoas. Desse modo, a psicologia, como exemplo, com fundamentação fenomenológica, vem se configurando em um campo de saber que bebe dessa fonte para pensar a pesquisa. E outros campos de saber também o fazem, aproximando seu escopo específico da fenomenologia. É nessa busca de pensar um método de pesquisa fenomenológica para a psicologia que Feijoo (2018) atesta a necessidade de inquirirmos verdades até então inquestionáveis referentes ao método da ciência moderna.

A respeito do método heideggeriano na filosofia, o qual é possível estender aqui para a ciência, Stein (1983, p. 9) afirma: "a hermenêutica filosófica que procura mostrar como a compreensão não é primeiramente um elemento metódico na interpretação dos textos, mas uma forma de exercício da vida social, vida que, em última análise, é uma comunidade de linguagem". Como assinala o autor, esta seria uma das direções que tornam possível uma compreensão da relação entre a

1 Apesar de necessário compreender aproximações e afastamentos entre as fenomenologias de Husserl e Heidegger para propor um método de pesquisa fenomenológico, este não é nosso objetivo nesse momento. Sugerimos a leitura do artigo a seguir para uma aproximação com essa questão: Link 
filosofia e as ciências, principalmente as ciências humanas.

Desse modo, e isso é imprescindível que se diga, ao se falar de um método fenomenológico de compreensão de um fenômeno, que não existe uma única forma de se investigar. Não existe uma única fenomenologia. Existem fenomenologias. Do mesmo modo, não existe somente um modo de pensar um caminho metodológico na fenomenologia. Eles são tão diversos quanto as várias compreensões do que seja a fenomenologia. Desse modo, falamos de fenomenologias, como veremos no decorrer deste artigo. Assim, enquanto Husserl busca apreender a essência dos fenômenos, compreendida como algo que não se perde, pois que independe do intérprete, Heidegger quer entender a vida e seus fenômenos desde si mesmo, no intuito de participar, e não "suspender" o próprio viver (Critelli, 1996; Frota \& Dutra, 2018; Silva, 2012).

Husserl buscou desenvolver um método investigativo que elevaria a filosofia à condição de ciência rigorosa. Para ele, o homem retorna para um dos polos do conhecimento através da redução transcendental, epockhé, buscando chegar à essência do fenômeno. Para tanto, afirma Silva (2000), desenvolveu uma fenomenologia transcendental. Já Heidegger caminha a partir de um eixo reflexivo, voltando à origem grega do pensamento do ser, indo em busca do começo do pensamento.

Para a fenomenologia heideggeriana, não existe uma verdade absoluta. Com isso, a verdade é compreendida como um desvelamento de sentidos, fluido e sempre parcial, levando-nos a pensar. A verdade é aletheia, contrapondo-se à veritas, que tão bem caracteriza a compreensão de verdade para o projeto da ciência moderna. Assim, propõe um movimento que significa indagar, questionar, tentar compreender. Para a fenomenologia, desse modo, o que se mostra, ou seja, a aparência é o próprio fenômeno, sujeito à produção de sentido dado pelo espectador. É mister deixar claro que a ela apresenta uma ruptura importante com o modelo da ciência moderna.

O Dasein se coloca como ponto de partida para qualquer pergunta, oferecendo-se como caminho para a fundamentação necessária para a produção do conhecimento. O Dasein coloca o homem no centro da estruturação do conhecimento. Desse modo, enfatiza Silva (2000), enquanto Husserl trata com um sujeito transcendental, via consciência e epockhé, Heidegger caminha com o Dasein como centro da estruturação do conhecimento.

Heidegger trouxe a hermenêutica para o centro da discussão filosófica, sendo categórico na crença de que o intérprete deve se deixar atravessar pela facticidade. Isto significa dizer que o Dasein se caracteriza por uma interpretação que lhe é própria e peculiar, que já se encontra lá antes de qualquer enunciado. Ele distancia-se de Husserl, colocando-se como um hermeneuta (Silva, 2012; Stein, 2014).

Em lugar da consciência, da intencionalidade, agora o que mais importa para Heidegger é o Dasein, o ser-aí, que acaba por nos levar ao domínio da existência, passando a se constituir como uma diferenciação entre a hermenêutica ontológica de Heidegger e a fenomenologia transcendental de Husserl, entendimento esse seguido por alguns autores, como Stein (1983) e Frota e Dutra (2018).

Assim, diferentemente de Husserl, Heidegger trouxe a certeza da impossibilidade de se recusar o caráter de historicidade das condições de conhecimento, distanciando-se da sua postura transcendental (Frota \& Dutra, 2018). Para o filósofo da Floresta Negra,

O ser-aí nunca passa primeiramente, no decurso de sua existência, de uma imanência para outro ente. O ser-aí nunca é de um modo tal que, em certa medida, viva no interior de uma cápsula; ele nunca é apenas sujeito no mau sentido. (Heidegger, 1996/2008, p. 128)

Nessa mesma direção, Silva (2012) considera importante marcar a diferença entre Husserl e Heidegger, afirmando que o primeiro teria permanecido preso na imanência da consciência. Eis suas palavras:

No essencial, a redução é um método ao abrigo do qual o mundo objetivo (incluindo o eu enquanto entidade psíquica) é posto entre parênteses, o que tem como resultado a revelação da consciência transcendental pura, a qual é a base de toda a doação de sentido e da constituição do mundo. Por outras palavras, a redução é o movimento que nos conduz do mundo exterior ao espaço interior da consciência (Silva, 2012, p. 153)

Ora, é justamente essa dualidade entre interior e exterior que Heidegger nega com sua noção de Dasein como ser-nomundo. Assim, torna-se inviável fazer redução, uma vez que o mundo não é algo que possa ser posto entre parênteses, visto que pertence à constituição ontológica do próprio Dasein.

Do mesmo modo, acrescenta Silva (2000), não se pode falar de interpretação sem pressupostos, que seria o ideal da descrição pura e da ausência de pressupostos, tal qual almejada por Husserl. Portanto, "ao contrário, pois, do que seria de se esperar de um sujeito transcendental, o Dasein é irredutivelmente mundano e radicalmente histórico" (Silva, 2000, p. 3). A imbricação com a história é marca da fenomenologia hermenêutica. Nas palavras de Feijoo (2018, p. 334): "Heidegger 
apropria-se do modo fenomenológico de investigação, ao mesmo tempo em que considera que o fenômeno se constitui circularmente em um determinado horizonte histórico".

A discussão acerca da proximidade e do afastamento entre a fenomenologia transcendental de Husserl e a hermenêutica ontológica de Heidegger merece o olhar criterioso de muitos pesquisadores e estudiosos, e não existe um único parecer. Para Missaggia (2011, p. 2), por exemplo,

Embora Heidegger afirme que sua filosofia é fenomenologia, e que trabalha de acordo com o método fenomenológico - o que, aliás, continuará a reiterar em Ser e Tempo e em obras posteriores - é evidente que o tipo de procedimento de que parte já excede em muito o método fenomenológico husserliano em sentido estrito.

Seguimos apontando alguns aspectos que, de acordo com alguns autores, como Missaggia (2011) e Stein (1983), mostram as diferenças dos caminhos seguidos por Heidegger e que o distanciam do seu mestre Husserl. A intencionalidade em Husserl é uma estrutura da consciência, já para Heidegger enraíza-se no horizonte da facticidade. "O Dasein como serno-mundo conduz à subversão da concepção husserliana da intencionalidade”, enfatiza Silva (2012, p. 160).

Sobre isso, Missaggia (2011, p. 2) define vida fática e diz: "Acreditamos que o contexto da formação da nova metodologia surge na busca por uma filosofia que permitisse o acesso à vida fáctica e concreta, no seu componente histórico, prático e inserido na chamada hermenêutica da facticidade". Desse modo, Heidegger funda sua fenomenologia na compreensão e na hermenêutica da vida fática. Esse modo de compreensão nos leva a pensar em um método de pesquisa que seja atravessado por ele. Algo como sugere Heidegger (1996/2008, p. 130): “(...) a pergunta principal acerca de como devemos afinal apreender esse outro ser-aí". Como dito anteriormente, Heidegger inaugura uma hermenêutica, diferenciando-se de Husserl (Frota \& Dutra, 2018). Assim, na fenomenologia de Heidegger, a "hermenêutica pressupõe o reconhecimento de uma estrutura ontológica (universal) do homem histórico. Somente a partir daí podemos avançar em qualquer interpretação" (Frota \& Dutra, 2018, p. 50).

Seguindo na esteira husserliana, e na busca por construir uma metodologia de pesquisa fenomenológica de inspiração husserliana, considera-se a necessidade de colocar entre parênteses os pressupostos teóricos anteriores à compreensão do fenômeno estudado. Nessa construção, Amedeo Giorgi é um dos pesquisadores mais usados na pesquisa inspirada em Husserl (Moreira \& Souza, 2016). Outros caminhos metodológicos, diferentes do estritamente husserliano, começam a ser delineados (Goze, Paiva, Bloc, Naudin, \& Moreira, 2019; Schneider, 2019). Seja na esteira da fenomenologia merleaupontyana, ou seja, de herança sartreana, a busca de construir caminhos de compreensão de uma realidade partindo dos fundamentos da fenomenologia segue seu percurso.

Por acreditar na compreensão do homem como ser-no-mundo, parece-nos contraditório pensá-lo de outro modo, uma vez que, para os pensadores da tradição heideggeriana, o homem é sendo. Desse modo, o sentido de um fenômeno que buscamos conhecer não é simplesmente descoberto nem criado. Não é algo exterior nem meramente subjetivo. Segue afirmando Silva (2012, pp. 165-166): "diríamos que o sentido é algo que exige de nós criação, para que deles possamos ter experiência”.

Em lugar da consciência, da intencionalidade, agora o que mais importa é o Dasein, o ser-aí, que acaba por nos levar ao domínio da existência, da facticidade, tal como nos asseguram Sá e Barreto (2011). Heidegger sugere uma compreensão voltada ao Dasein, como centro de toda estruturação do conhecimento (Silva, 2012). Fala, portanto, de um lugar diferente que seu mestre, Husserl, ocupou.

Feijoo (2018) se junta aos autores que discutem sobre a possibilidade de um método de pesquisa na psicologia, tendo como fundamento a concepção de método pensada pelo filósofo Martin Heidegger em sua analítica da existência. Pensando sobre isso, ela afirma: "Nós consideramos que a atitude fenomenológica nos permite ir ao fenômeno tal como ele se mostra, e que o elemento hermenêutico em si mesmo é a condição do Dasein que já sempre se compreende em seu ser" (Feijoo, 2018, p. 331). Essa fala da autora nos remete tanto à compreensão quanto à disposição afetiva, ao Befindlichkeit, já tematizado por Dutra (2016).

No pensamento do filósofo, Befindlichkeit, ou disposição afetiva, é um existencial que, junto com a compreensão e a linguagem, estão presentes em todas as situações existenciais, ou seja, na experiência, uma vez que esta, a experiência, representa a própria existência, no sentido de ek-sistere, ou ser-para-fora, em abertura. A experiência de estar com um outro na relação pesquisador-pesquisado é, antes de tudo, uma experiência de ser-no-mundo-com-outro, própria do Dasein. Portanto, é atravessada sempre por alguma tonalidade afetiva, por um humor ou sentimento, tal como proposto por Gendlin (1978/1979) e retomado por Dutra (2016).

De acordo com Heidegger (1927/2015, p. 35), o Befindlichkeit se relaciona com o método, pois "é a revelação da qual o método fenomenológico depende". Se a descoberta do Befindlichkeit não está lá como parte do método, então não haverá fenomenologia, mas uma livre-flutuação. Silva (2012, p. 166) também acredita nisso, afirmando: "Segundo Heidegger, os entes manifestam-se no âmbito da abertura (Erschlossenheit) do Dasein. Tal abertura é constituída por dois existenciários fundamentais: a disposição afetiva (Befindlichkeit) e a compreensão (Verstehen)". 
É importante ressaltar igualmente o lugar da compreensão, esse existencial, o qual nos permite entender que, quando interpretamos, é porque já compreendemos, como diz o filósofo em Ser e Tempo (Heidegger, 1927/2015), e que, em todas as situações nos apresentadas, temos uma compreensão do mundo de acordo com a atmosfera ou tonalidade afetiva que nos envolve e manifesta os sentidos dos quais nos apropriamos e, por outro lado, refletem o horizonte histórico do nosso tempo.

Aliado às ideias apresentadas anteriormente, sobretudo se adotarmos o primado do ocultamento-desvelamento, dificilmente será possível existir um método de pesquisa que pretenda alcançar uma verdade absoluta ou uma evidência científica da existência que possa ser generalizada e objetivada, tal como propõe no método científico da ciência moderna, que se fundamenta em paradigmas das ciências naturais, como bem mostra Dilthey (2011).

Com isso, podemos dizer que o método de pesquisa fenomenológica hermenêutica se constitui em uma possibilidade de busca de conhecimento rigoroso, valorizando a experiência e o modo como o sujeito a significa. Enfatiza o ser e a dimensão existencial do viver, buscando compreender sentidos e significados. Sinaliza que, para se conhecer uma realidade, é necessário entender a vida e seus fenômenos a partir de si mesmo e de suas próprias vivências. Desse modo, é a partir da existência que compreenderemos o ser-no-mundo. Tais ideias se constituirão em fundamentos para se pensar um método de pesquisa, tal como propomos neste texto.

Apesar das reflexões que vimos desenvolvendo acima, é fato que Heidegger não construiu um método de pesquisa. É bem verdade que Heidegger (1927/2015), no parágrafo 7, trata do método fenomenológico da investigação, falandonos de fenômeno, logos e fenomenologia. No entanto, como não poderia ser diferente, já que seu intuito é nos apresentar seus conceitos fundamentais, não se aprofundou nesse caminho. Sua compreensão maior era acerca do novo modo de conceber a questão do ser, enfatiza Stein (2014). Não obstante isso, consideramos possível e necessário, pelo menos para nós, interessados na pesquisa fenomenológica hermenêutica de inspiração heideggeriana, que pensemos em elementos possibilitadores de construção de um caminho que proporcione uma aproximação do fenômeno a partir dessa lente.

$\mathrm{Na}$ tentativa de chegar mais perto dessa construção, passamos a refletir acerca da fenomenologia hermenêutica, dialogando com Heidegger, esclarecendo elementos da sua ontologia, os quais dão suporte filosófico a esse modo de pensar uma metodologia de inspiração heideggeriana. Não podemos esquecer que Heidegger (1987/2001, p. 229), referindo-se à psicologia, diz que

Neste âmbito não é possível provar nada. É preciso renunciar à ideia de que só o que pode ser provado é a verdade. Há coisas como a presença ou a liberdade que rejeitam qualquer exigência de mensurabilidade. Não se trata de uma teoria, mas de uma visão daquilo que nós mesmos já sempre somos.

Possivelmente considerando que é possível pensar e construir um método de pesquisa que se inspirasse nas suas ideias, fazemos uso das palavras de Heidegger (1987/2001, p. 137) para nos conclamar na busca do caminho:

O envolver-se é um caminho inteiramente diferente, um método muito diferente do que o método científico, se soubermos usar a palavra método em seu sentido original, verdadeiro ver (meta odos), o caminho para. A este respeito os senhores precisam se afastar do conceito comumente dado de método como uma simples técnica de pesquisa.

Deparamo-nos, assim, num caminhar por estradas ainda em construção, terrenos por vezes áridos e esburacados. Mas, em vez de muros, buscamos pontes. Desse modo, seguimos.

\section{Construindo Formas de Acessar o Fenômeno: A Hermenêutica da Facticidade de Heidegger}

A fenomenologia hermenêutica de Heidegger abre a possibilidade de construir vias de acesso às compreensões de um fenômeno qualquer. Apesar de não ter se detido à construção de um método, o filósofo inspira essa tessitura. Para tanto, partimos de alguns de seus pressupostos filosóficos, que nos darão uma sustentação para essa incursão teórica.

Dentre as estruturas de possibilidades que fazem parte do humano, está o sernomundo como a mais básica delas. Seguem-se a temporalidade, a espacialidade, o encontrar-se, o compreender e a fala. Ao Dasein é impossível ser sem sernomundo, que é sua constituição fundamental.

Heidegger (1927/2015) assegura que o homem é mundano, que ele é através do mundo. O Dasein é ser-aí, é estar-aíjunto-com-os-outros. O homem é seu próprio mundo. Ele é junto aos outros, habitando o mundo, cuidando de ser. Existe, pois, uma indissolúvel ligação entre o homem e o mundo. Além disso, a vida é dada ao homem como possibilidade, sob determinadas condições, não existindo qualquer substrato anterior que lhe dê alguma segurança. O Dasein é um vir-a-ser, significando que tem que cuidar de si. A responsabilidade pelo cuidar de ser é condição humana, básica e intransferível. 
O homem realiza o cuidar pelo tempo, que nos é dado como condição de vida. É um ser-para-a-morte, e é a partir do morrer que se abre a condição de vida. O cuidar da vida é temporalizado. O existir humano é o de um ser ek-sistindo, indo para algum lugar. Assim, o homem se esgota no tempo. A temporalidade é, pois, uma condição de ser. No entanto, para Heidegger, a temporalidade não é a cronológica, e sim acontecimental.

Com a espacialidade se revela a capacidade que o homem tem de se aproximar e se afastar das coisas. Todos os afetos contribuem para o afastamento ou a aproximação. Também deles dependem as escolhas e o modo de estar-no-mundo. Já com o encontrar-se, com a disposição de humores, revela-se o modo como encontramos o mundo e a nós mesmos. São a sensação e os estados de ânimo que dão consistência ao mundo.

No entanto, enquanto afetos como tédio, alegria e esperança traduzem uma aparência do cotidiano, somente a angústia, como disposição fundamental, tal como afirma Heidegger (1927/2015), põe-nos em contato com o que de mais próprio existe em nós mesmos. Assegura Heidegger (1927/2015, p. 249): “Aquilo com que a angústia se angustia é o ser-no-mundo como tal". E mais à frente: "A angústia singulariza o Dasein em seu próprio ser-no-mundo que, na compreensão, se projeta essencialmente para possibilidade" (Heidegger, 1927/2015, p. 251).

Finalmente, como condição ontológica, o falar revela a capacidade que o homem tem de compreender e expressar o que se mostra. O discurso é constitutivo do ser-no-mundo, uma vez que a linguagem é uma forma essencialmente mundana. Isto é o mesmo que afirmar que o homem é falante, já que, para Heidegger (1959/2003, p. 7), o Dasein é linguagem:

O homem fala. Falamos quando acordados e em sonho. Falamos continuamente. Falamos mesmo quando não deixamos soar nenhuma palavra. Falamos quando ouvimos e lemos. Falamos igualmente quando não ouvimos e não lemos e, ao invés, realizamos um trabalho e ficamos à toa. Falamos sempre, de um jeito ou de outro.

Partindo dessa compreensão, Heidegger, com sua fenomenologia ontológica, aponta uma possibilidade real de acessar um fenômeno concreto, a partir de sua onticidade. Na busca de conhecer um fenômeno, compreendemos que existe uma indissociabilidade entre o que se mostra e quem o vê, deixando clara a impossibilidade de qualquer tentativa de objetividade ou separação entre eles.

A partir da obra heideggeriana, fica claro que qualquer compreensão humana se orienta a partir de uma pré-compreensão. Desse modo, Heidegger foi o responsável por desenvolver a fenomenologia hermenêutica (Gadamer, 1997; Silva, 2012; Stein, 2014). Segue dizendo Stein (2014, p. 204): "Compreendemos a hermenêutica não como um ataque à razão, mas como um modo de análise que considera os aspectos históricos relacionados às tentativas de fundamentação de conhecimento", trazendo a certeza da impossibilidade de recusar o caráter de historicidade das condições de conhecimento. Desse modo, "enquanto uma tentativa de desenvolver uma teoria filosófica de compreensão, a partir da analítica existencial, Heidegger inaugurou um novo paradigma filosófico" (Stein, 2014, p. 224).

O Dasein é mundano e histórico e, somente a partir dessa compreensão fática que o constitui, ele compreende e interpreta o mundo. O Dasein é, desse modo, o ponto de partida de qualquer interpretação. A partir do Heidegger tardio existe uma clara preocupação com a linguagem, que se torna um lugar privilegiado de manifestação do ser. Desde então, asseguram Gondin e Rodrigues (2009), Heidegger deixa de se perguntar pelo sentido do ser para refletir sobre a verdade do ser. Afirmam: "Compreender a filosofia do segundo Heidegger é mudar o sentido da orientação, do olhar e da escuta. É fazer uma ligação primeira entre o pensar, o ser, o homem e a linguagem" (Gondin \& Rodrigues, 2009, p. 92). Desse modo, o sentido de um texto é o que pode ser articulado na compreensão, ou seja, no discurso. É a linguagem que nos abre o ser-no-mundo.

Já na compreensão, o ser existe como possibilidade de ser, nos modos de ocupação com o mundo, de pré-ocupação com os outros, mas, fundamentalmente, na possibilidade de ser para si mesmo. Assim, o Dasein está lançado a este poderser, à faticidade. Para Heidegger (1927/2015, p. 200), “compreender é o ser existencial do próprio poder-ser da pre-sença de tal maneira que, em si mesmo, esse ser abre e mostra a quantas anda seu próprio ser.” Nessa perspectiva, o Dasein já se compreendeu e sempre se compreenderá a partir de possibilidades. É no humor que o Dasein vê possibilidades a partir das quais ele já é. Portanto, afirma Azevedo (2013, p. 82), "por ser ser-no-mundo o Dasein já se comportou em relação ao ser dos entes numa relação significativa, numa trama de significações".

A interpretação é a elaboração do projeto da compreensão como possibilidade, afirma Heidegger (1927/2015). Compreender é sempre interpretar, uma vez que, ao compreendermos algo, estamos interpretando. Além disso, a análise da estrutura da interpretação revela uma integração de três momentos fundamentais: (1) posição prévia - possibilitada pelo horizonte das articulações; (2) visão prévia - que designa a perspectiva em que se encara e vê o conjunto das articulações; e (3) concepção prévia - apreensão do conjunto de posições e visões prévias.

Com isso, estamos falando do círculo hermenêutico, a partir do qual a busca de sentido de um fenômeno implica mergulhar no entrelaçamento significativo das redes que revelam a inserção do ser-no-mundo a partir do olhar do pesquisador. Desse modo, o círculo hermenêutico "permite o conhecimento mais originário, que só pode ser apreendido de modo autêntico se 
a interpretação tiver compreendido que sua única tarefa é não se deixar guiar por chutes ou conceitos ingênuos" (Frota \& Dutra, 2018, p. 54). A interpretação hermenêutica sugere uma postura flexível do pesquisador, a qual é "atravessada pelas afetações da experiência e pelas necessidades que podem surgir progressivamente, distanciando-se da tentativa de controle dos fenômenos" (Silva, 2018, p. 147).

Para Heidegger (1927/2015), a compreensão se completa na interpretação, que decorre de uma pré-compreensão. Nesse sentido, ela se dá a partir de um círculo, hermenêutico, que tem um caráter universal. A mirada fenomenológica é intencional e determinada pela vida fática. Portanto, sua tarefa é a interpretação da facticidade desde si mesmo (Maza, 2005).

Uma possibilidade de interpretação fenomenológica com inspiração heideggeriana, conforme pensada neste artigo, encontra-se dentro de uma circularidade hermenêutica. É importante lembrar que a proposta de Heidegger era pensar a ontologia, a questão do ser. Assim, partimos do fundamento ontológico para pensarmos a onticidade. Esse movimento de ir da ontologia para a onticidade e vice-versa deixa clara a impossibilidade de separar os dois campos.

Heidegger parte da estrutura ontológica do círculo hermenêutico, considerado como status de universalidade. Desse modo, toda compreensão de um fenômeno se efetua sob motivações, pré-concepções, enfim, sob uma visada précompreensiva. O filósofo leva a cabo o tratamento fenomenológico-hermenêutico da facticidade, acreditando que não importa tanto o nosso fazer quanto o que acontece na nossa caminhada de pesquisador.

A partir de Heidegger, atesta Silva (2013, p. 56), o círculo hermenêutico ganha dimensão existencial, pois "já não se limita à tese da interdependência entre a interpretação das partes e a interpretação do todo, pois refere-se sobretudo à relação circular entre a pré-compreensão do intérprete, (incluindo a sua auto-compreensão) e o interpretandum".

A partir dessa compreensão, Heidegger inverte a relação tradicional entre interpretação e compreensão. A interpretação se funda na compreensão. Assim, sempre estamos compreendendo e interpretando. A interpretação passa a ser considerada uma elaboração ou exploração de possibilidades. Segue afirmando Silva (2013, p. 57):

Dado que a interpretação permanece sempre condicionada pela pré-compreensão do intérprete, o processo interpretativo é interminável, razão pela qual Heidegger, em vez de aspirar à objetividade, se limita a alertar contra a interferência de ideais ocasionais e conceitos populares, apelando simultaneamente a que se desenvolva a partir das próprias coisas.

Falamos do círculo hermenêutico heideggeriano como inspiração de construção de um método de pesquisa, através do qual se dá um não e um sim à técnica, como já denunciou Heidegger (1927/2015). Precisamos vislumbrar caminhos que nos possibilitem interpretar e compreender fenômenos e, ao mesmo tempo, necessitamos estar atentos para não cairmos no erro de apresentarmos modelos fechados, rígidos, técnicos (Tolfo, 2010).

Segundo essa perspectiva, o autor propõe quatro passos para se pensar um método fenomenológico. No entanto, ao sugerir estágios ou passos, corremos um risco de nos embrenharmos na técnica e nos perdermos na impropriedade, esquecendo a fluidez do velamento e desvelamento da aletheia. Não podemos perder de vista que o círculo hermenêutico trata de movimentos, circulares e inacabados, que não se esgotam em si mesmos. Desse modo, cada interpretação que se faz é parcial, incompleta, transitória. Não pode ser tomada como técnica, e sim como inspiração.

A partir dessa compreensão, Azevedo (2013) e Maux (2014) sugerem alguns movimentos que possibilitam compreender e interpretar um fenômeno: entrevista narrativa, tal como proposta por Dutra (2002), com registro das afetações vividas pelo pesquisador; transcrição e literalização das narrativas; elaboração do texto interpretativo; desvelamento de temas a serem interpretados; e diálogo entre o texto interpretativo, autores escolhidos como sustentação teórica e o olhar meditante do pesquisador.

Que fique claro, portanto, que a interpretação possibilitada pelo círculo hermenêutico, tal como sugerido por Heidegger, configura-se sempre numa possibilidade de compreensão. Daí a impossibilidade de ser compreendida como uma técnica a ser copiada acriticamente. Nessa perspectiva, cada pesquisa se constrói passo a passo; cada método, compreendido como caminho, faz-se na interação pesquisador-pesquisado. Enfim, cada interpretação é única.

\section{A Hermenêutica Filosófica - Uma Possibilidade de Método para a Pesquisa de Inspiração Heideggeriana - Algumas Considerações para Abrir Novas Conversas}

A hermenêutica é o reconhecimento de uma estrutura ontológica universal do homem histórico. Somente a partir desse ponto inicial é possível se pensar em um caminho para interpretar um fenômeno qualquer. Heidegger nos fala de uma hermenêtica existencial da factcidade, significando que o Dasein se caracteriza por uma interpretação que lhe é peculiar e que se encontra presente antes de qualquer enunciado. Assim, deixar-se determinar pela própria coisa é tarefa primeira, constante e única do intérprete.

Heidegger, parece-nos, sai do presente tecnicizado, buscando os fundamentos do ser. Como fazer algo assim na pesquisa empírica? Como partir do ôntico sem perder de vista sua ontologia? A pista sugerida pelo filósofo é tomar o Dasein como 
ponto de partida para qualquer pergunta e produção de conhecimento. Por perceber a impossibilidade do projeto de repensar o sentido do ser em termos da ontologia transcendental, busca uma articulação do sentido no mundo da vida.

Desse modo, aceita a experiência prévia, os conceitos anteriores e os preconceitos, como fazendo parte da facticidade. Propõe o caráter de circularidade como modo de ser no mundo, de cuidado, sempre atravessado pelas estruturas prévias da interpretação. Nessa direção, o sentido de um texto é o que pode ser articulado na compreensão, aberta pela linguagem.

Para Heidegger, como o mundo não é algo que possa ser posto entre parênteses, visto que pertence à constituição ontológica do próprio Dasein, somente é possível compreender e interpretar um fenômeno qualquer a partir da procura de um sentido para a vida ou existência: "A rejeição de uma intelegibilidade exterior à capacidade humana de articulação do sentido e o caráter universal da compreensão" (Silva, 2012, p. 166).

O círculo hermenêutico aponta para um retorno às coisas mesmas que, para Heidegger, referem-se aos entes. Posição prévia, visão prévia e concepção prévia são, portanto, movimentos que se oferecem como elementos que intermediam a interpretação da facticidade desde si mesmo. Nessa direção, talvez mais importante do que o resultado de uma pesquisa seja o que acontece no seu caminhar.

Finalmente, já que é impossível concluir, convidamos os leitores a pensarem na possibilidade de, a partir de uma inspiração heideggeriana, construírem caminhos metodológicos de compreensão empírica que não se perca da ontologia. Com a certeza de que Heidegger (1927/2015) está certo ao afirmar que o mostrar-se não é um mostrar-se qualquer, seguimos em busca de uma fenomenologia que acesse o ser dos entes via compreensão e interpretação.

\section{Referências}

Andrade, C. C., \& Holanda, A. F. (2010). Apontamentos sobre pesquisa qualitativa e pesquisa empírico-fenomenológica. Revista Estudos de Psicologia (Campinas), 27(2), 259-268.

Azevedo, A. K. (2013). Não há você sem mim: Histórias de mulheres sobreviventes de uma tentativa de homicídio. Tese de Doutorado, Programa de Pós-graduação em Psicologia, Universidade Federal do Rio Grande do Norte, RN.

Casanova, M. (2011). Introdução. In W. Dilthey, Ideias sobre uma psicologia descritiva e analítica. M. A. Casanova, Trad., (pp. 7-22). Rio de Janeiro: Via Verita.

Critelli, D. (1996). Analítica do sentido: Uma aproximação e interpretação do real. São Paulo: Brasiliense.

DeCastro, T. G., \& Gomes, W. B. (2011). Aplicações do método fenomenológico à pesquisa em psicologia: tradições e tendências. Estudos de Psicologia, 28(2), 153-161.

Dilthey, W. (2011). Ideias sobre uma psicologia descritiva e analitica (M. A. Casanova, Trad.). Rio de Janeiro: Via Verita.

Dutra, E. (2002). A narrativa como técnica de pesquisa fenomenológica. Estudos de Psicologia (Natal), 7(2), 371-378.

Dutra, E. (2016). Rogers and Heidegger: Is a gathering for a new view of the self possible? Revista Estudos de Psicologia (Campinas), 33(3), 413-423.

Feijoo, A. M. L. C. (2018). Metà-Hodós: Da fenomenologia hermenêutica à psicologia. Phenomenological Studies - Revista da Abordagem Gestáltica, 24(3), 329-339.

Feijoo, A. M. L. C., \& Goto, T. A. (2016). É possível a Fenomenologia de Husserl como método de pesquisa em Psicologia? Psicologia: Teoria e Pesquisa, 32(4), 1-9.

Frota, A. M. M. C., \& Dutra, E. (2018). Encontros e (des)encontros entre as hermenêuticas de Heidegger e Gadamer. In E. Dutra (Org.). O Dessassosego humano na contemporaneidade (pp. 45-68). Rio de Janeiro: Via Veritas.

Gadamer, H. (1997). Verdade e método: Traços fundamentais de uma hermenêutica filosófica. Petrópolis, RJ: Vozes.

Gendlin, E. (1978/1979). Befindlickeit: Heidegger and the philosophy of Psychology. Journal of Existential Psychology and Psychiatry, 16(1-3), 43-71. 
Gondin, E., \& Rodrigues, O. (2009). O Transcendentalismo de Heidegger: Um resumo. Revista de Humanidades e Ciências Sociais, 5. Link

Goze, T., Paiva, J., Bloc, L., Naudin, J., \& Moreira, V. (2019). A fenomenologia como base epistemológica e ética do movimento desalienista na França e no Brasil. Phenomenological Studies - Revista da Abordagem Gestáltica, 25(3), 274-281.

Heidegger, M. (2001). Seminários de Zollikon. Petrópolis, RJ: Vozes. (Originalmente publicado em 1987)

Heidegger, M. (2003). A caminho da linguagem. Petrópolis: Vozes. (Originalmente publicado em 1959)

Heidegger, M. (2008). Introdução à filosofia. São Paulo: Martins Fontes. (Originalmente publicado em 1996)

Heidegger, M. (2015). Ser e Tempo. Petrópolis: Vozes. (Originalmente publicado em 1927)

Husserl, E. (2014a). Interpretações lógicas prolegômenos à lógica. São Paulo: Forense Universitária. (Originalmente publicado em 1900)

Husserl, E. (2014b). Investigações para a fenomenologia e a teoria do conhecimento. São Paulo: Forense Universitária. (Originalmente publicado em 1901)

Maux, A. A. B. (2014). Masculinidade à prova: um estudo de inspiração fenomenológico-hermenêutico sobre a infertilidade masculina. Tese de Doutorado, Programa de Pós-graduação em Psicologia, Universidade Federal do Rio Grande do Norte, RN.

Maza, L. M. (2005). Fundamentos de la filosofía hermenêutica: Heidegger y Gadamer. Revista Teologia y Vida, XLVI, 122-138.

Missaggia, J. O. (2011). As origens do método heideggeriano: o desenvolvimento das indicações formais. Dissertação de Mestrado, Programa de Pós-graduação em Filosofia, Pontifícia Universidade Católica do Rio Grande do Sul, RS.

Moreira, R. B., \& Souza, A. M. (2016). Contribuições do método fenomenológico empírico para estudos em psicologia no Brasil: Revisão integrativa da literatura. Revista NUFEN, 8(1).

Moreira, V. (2004). O método fenomenológico de Merleau-Ponty como ferramenta crítica na pesquisa em Psicopatologia. Psicologia: reflexão e crítica, 17(3), 447- 456.

Sá, R. N., \& Barreto, C. L. B. (2011). A noção fenomenológica de existência e as práticas psicológicas clínicas. Revista Estudos de Psicologia (Campinas), 28(3).

Schneider, D. R. (2019). Caminhos históricos e epistemológicos da psicopatologia: contribuições da fenomenologia e existencialismo. Cadernos Brasileiros de Saúde Mental, 1(2), 62-76.

Silva, E. F. G. (2018). Pesquisa qualitativa em psicologia clínica: uma possibilidade metodológica em diálogo com a fenomenologia hermenêutica. Revista Pesquisa Qualitativa, 6(11), 145-159.

Silva, R. S. (2000). Gadamer e a Herança Heideggeriana. Revista Portuguesa de Filosofia, 56, 521-541.

Silva, R. S. (2012). Sentido, interpretação e verdade: Uma perspectiva analítica e hermenêutica. Lisboa: Centro de Filosofia da Universidade de Lisboa.

Silva, R. S. (2013). O círculo hermenêutico e a distinção entre ciências humana se ciências naturais. Ektasis: Revista de Fenomenologia e Hermenêutica, 1(2), 54-72.

Stein, E. (1983). A questão do método na Filosofia: Um estudo do modelo heideggeriano. Porto Alegre: Movimento. 
Stein, E. (2014). Gadamer e a Consumação da Hermenêutica. Problemata: Revista Internacional Filosofia, 5(1), 204-226.

Tolfo, R. (2010). Os quatro estágios do método fenomenológico em Ser e Tempo de Martin Heidegger, de acordo com Heidegger e o problema do conhecimento de Charles Guignon [Resumo]. In Universidade Estadual de Santa Cruz (Org.). Resumos do IV Seminário de História e Filosofia da Ciência (p. 8). Ilhéus: UESC.

\section{Como citar:}

Frota, A. M. M. C., e Dutra, E. (2021). Proposições para um Método Fenomenológico Hermenêutico para a Pesquisa de Campo. Revista Subjetividades, 21(Esp 1. Psicologia \& Fenomenologia), e11305. http://doi.org/10.5020/23590777. rs.v21iEsp1.e11305

\section{Endereço para correspondência}

Ana Maria Monte Coelho Frota

E-mail: anafrota@ufc.br

Elza Maria Socorro Dutra

E-mail: elzadutra.rn@gmail.com 